\title{
TEA Domain Transcription Factor 4 Is the Major Mediator of Yes-Associated Protein Oncogenic Activity in Mouse and Human Hepatoblastoma
}

Jie Zhang, ${ }^{* \dagger}$ Pin Liu, ${ }^{\ddagger}$ Junyan Tao, ${ }^{\S}$ Pan Wang, ${ }^{\dagger \oplus ~ Y i ~ Z h a n g, ~}{ }^{\dagger}$ Xinhua Song, ${ }^{\dagger}$ Li Che, ${ }^{\dagger}$ Pavel Sumazin, ${ }^{\|}$Silvia Ribback, ** Andras Kiss, ${ }^{\dagger \dagger}$ Zsuzsa Schaff, ${ }^{\dagger \dagger}$ Antonio Cigliano, ${ }^{\star \star}$ Frank Dombrowski, ${ }^{* *}$ Carla Cossu, ${ }^{\S \S}$ Rosa M. Pascale, ${ }^{\S \S}$ Diego F. Calvisi, ${ }^{* *}$ Satdarshan P. Monga, ${ }^{\S}$ and Xin Chen

\begin{abstract}
From the Department of Thoracic Oncology II,* Key Laboratory of Carcinogenesis and Translational Research (Ministry of Education), Peking University Cancer Hospital and Institute, Beijing, People's Republic of China; the Department of Bioengineering and Therapeutic Sciences and Liver Center, ${ }^{\dagger}$ University of California, San Francisco, San Francisco, California; the Department of Pediatrics, ${ }^{\ddagger}$ Zhongnan Hospital of Wuhan University, Wuhan, People’s Republic of China; the Department of Pathology, ${ }^{\S}$ University of Pittsburgh, Pittsburgh, Pennsylvania; the Beijing Advanced Innovation Center for Food Nutrition and Human Health, "College of Food Science and Nutritional Engineering, China Agricultural University, Beijing, People's Republic of China; the Texas Children's Cancer Center, Baylor College of Medicine, Houston, Texas; the Institute of Pathology, ** University of Greifswald, Greifswald, Germany; the Second Department of Pathology, ${ }^{\dagger \dagger}$ Semmelweis University, Budapest, Hungary; the National Institute of Gastroenterology S. de Bellis, ${ }^{\ddagger \ddagger}$ Research Hospital, Castellana Grotte, Italy; and the Department of Medical, Surgical, and Experimental Sciences, ${ }^{\circledR \S}$ University of Sassari, Sassari, Italy
\end{abstract}

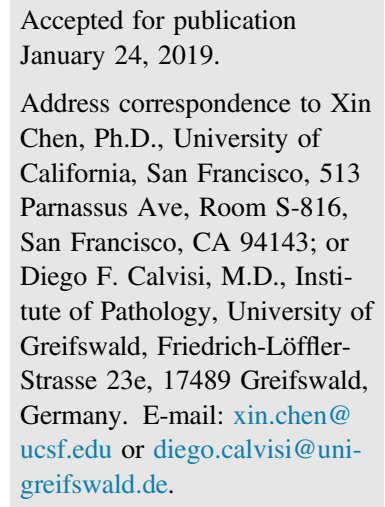

Hepatoblastoma (HB) is the most common type of pediatric liver cancer. Activation of yes-associated protein (YAP) has been implicated in HB molecular pathogenesis. The transcriptional co-activator Yap regulates downstream gene expression through interaction with the TEA domain (TEAD) proteins. Nonetheless, YAP also displays functions that are independent of its transcriptional activity. The underlying molecular mechanisms by which Yap promotes HB development remain elusive. In the current study, we demonstrated that blocking TEAD function via the dominant-negative form of TEAD2 abolishes Yap-driven HB formation in mice and restrains human HB growth in vitro. When TEAD2 DNAbinding domain was fused with virus protein 16 transcriptional activation domain, it synergized with activated $\beta$-catenin to promote HB formation in vivo. Among TEAD genes, silencing of TEAD4 consistently inhibited tumor growth and Yap target gene expression in HB cell lines. Furthermore, TEAD4 mRNA expression was significantly higher in human HB lesions when compared with corresponding nontumorous liver tissues. Human HB specimens also exhibited strong nuclear immunoreactivity for TEAD4. Altogether, data demonstrate that TEAD-mediated transcriptional activity is both sufficient and necessary for Yap-driven HB development. TEAD4 is the major TEAD isoform and Yap partner in human HB. Targeting TEAD4 may represent an effective treatment option for human HB. (Am J Pathol 2019, 189: 1077-1090; https://doi.org/10.1016/j.ajpath.2019.01.016)
Hepatoblastoma $(\mathrm{HB})$ is the most common pediatric liver cancer, with the highest incidence in children occurring before the age of 5 years. Approximately 100 cases of HB are diagnosed in the United States each year. ${ }^{1}$ Several risk factors associated with HB development have been identified, including low birth weight, familial adenomatous polyposis, and Beckwith-Wiedemann syndrome. ${ }^{2,3}$ The clinical management of HB has evolved significantly over the past three decades. ${ }^{4,5}$ Neoadjuvant chemotherapy and surgical resection are the standard treatment options for HB. However, drug resistance and distal metastases frequently develop in patients with high-risk $\mathrm{HB}$, often precluding the success of treatments.

HB is histologically divided into epithelial and mixed epithelial/mesenchymal subtypes. ${ }^{3,6}$ The epithelial subtype,

Supported by NIH grants R01CA204586 (S.P.M. and X.C.) and P30DK026743 (University of California, San Francisco Liver Center); and National Nature Science Foundation of China grant 81802774 (P.L.).

J.Z. and P.L. contributed equally to this work.

Disclosures: None declared. 
consisting of embryonic and fetal tumor cells, is the most frequently occurring HB histotype. ${ }^{3}$ The molecular mechanisms responsible for HB development remain poorly understood. Genome-wide analyses recently provided a global genomic landscape of genetic events occurring in human HBs. $^{7-9}$ Among them, mutations in the $\beta$-catenin gene $(C T N N B 1)$ are identified in $>80 \%$ of HBs, suggesting that activation of the $\mathrm{Wnt} / \beta$-catenin signaling cascade is the dominant driver oncogenic event along HB development and progression. ${ }^{10,11}$ Specifically, point mutations in exon 3 or large deletions in the N-terminal region of the CTNNBI gene are found. $\beta$-Catenin mutations cause nuclear translocation and enhance the stabilization of $\beta$-catenin protein. ${ }^{10,11}$ Subsequently, $\beta$-catenin interacts with nuclear cofactors of the T-cell factor/lymphoid enhancer-binding factor family to induce target gene expression. Intriguingly, mouse studies revealed that overexpression of activated forms of $\beta$-catenin in the mouse liver is insufficient to induce HB formation in vivo, ${ }^{12}$ strongly suggesting that additional molecular events cooperating with activated $\beta$-catenin are necessary to promote HB tumorigenesis.

The Hippo/yes-associated protein (YAP) cascade is a critical pathway in HB development. ${ }^{13}$ The Hippo signaling is an evolutionarily conserved cascade playing a vital role in tissue growth, organ size control, and tumorigenesis. ${ }^{14,15}$ YAP and its paralog transcriptional co-activator with PDZ-binding motif (TAZ) are the two major effectors downstream of Hippo kinases and act as transcriptional coactivators. ${ }^{14,15}$ In the canonical Hippo cascade, large tumor suppressor kinase 1/2, the mammalian Hippo kinases, phosphorylate and inactivate YAP/TAZ. When Hippo kinases are inhibited, YAP/TAZ become dephosphorylated and stabilized. Consequently, YAP/TAZ can translocate into the nucleus, interacting with DNA-binding transcription factors, particularly of the TEA domain (TEAD) family, to activate downstream gene expression and cell growth and survival. ${ }^{14,15}$ There are four TEAD genes in mammals (namely, TEAD1, TEAD2, TEAD3, and TEAD4). TEAD transcription factors share similar DNA-binding motifs and may function to regulate a similar set of genes. ${ }^{16,17}$ However, each TEAD gene has its own tissue distinctive expression, leading to the tissue-specific role for each TEAD protein. ${ }^{16}$ Although TEAD-mediated transcriptional regulation has been solidly proved to be a major oncogenic mechanism downstream of YAP/TAZ, mounting evidence indicates that YAP/TAZ possess additional functions independent of TEAD. ${ }^{18}$ For instance, YAP/TAZ can be incorporated in the $\beta$-catenin destruction complex and modulate the $\mathrm{Wnt} / \beta$-catenin signaling. ${ }^{19}$ Furthermore, cytoplasmic pools of YAP/TAZ could sequester SMAD proteins and subsequently regulate the transforming growth factor- $\beta$ signaling. ${ }^{20}$ Also, YAP/TAZ bind to Snail/Slug and regulate skeletal stem cell self-renewal and differentiation. ${ }^{21}$

In $\mathrm{HB}, \mathrm{YAP}$ is activated (as indicated by its nuclear localization) in approximately $80 \%$ of human $\mathrm{HB}$ samples. ${ }^{13}$ More important, coordinated and almost ubiquitous
Yap and $\beta$-catenin activation was only detected in human $\mathrm{HB}$, but not in other malignant liver lesions, such as hepatocellular carcinoma or cholangiocarcinoma, implying the critical role of the two pathways in combination only in pediatric liver cancer. ${ }^{13}$ In accordance with this hypothesis, using hydrodynamic tail vein injection, it was demonstrated that co-expression of activated forms of Yap (YapS127A) and $\beta$-catenin $(\Delta \mathrm{N} 90-\beta$-catenin) leads to the exclusive development of pure HB, but not other tumor types, in the mouse liver. ${ }^{13}$ On the basis of studies in vitro and in vivo, we investigated herein whether YAP oncogenic activity depends on its interactions with TEAD factors in HB. The data obtained indicate that TEAD-mediated transcriptional regulation is required for Yap-driven HB development, and TEAD4 may be the major TEAD isoform in human HB, thus representing a potential therapeutic target in this pediatric malignancy.

\section{Materials and Methods}

\section{Plasmids and Reagents}

The plasmids used in the experiments, including pT3-EF1 $\alpha$ $\Delta$ N90- $\beta$-catenin, pT3-EF1 $\alpha$-YapS127A, and pCMV-sleeping beauty transposase, were described in detail previously. ${ }^{13,22-24}$ The dominant-negative form of TEAD2 (dnTEAD2) construct $^{25}$ was kindly provided by Dr. Duojia Pan (Johns Hopkins University, Baltimore, MD). The TEAD2 DNAbinding domain fused with the virus protein 16 (VP16) transcriptional activation domain (TEAD2VP16) was purchased from Riken BioResource Center (Ibaraki, Japan). The dnTEAD2 and TEAD2VP16 plasmids were cloned into the pT3-EF1 $\alpha$ vector via the Gateway cloning technology (Invitrogen, Carlsbad, CA). All plasmids for in vivo experiments were purified with the GenElute HP Endotoxin-Free Maxiprep kit (Sigma-Aldrich, St. Louis, MO). In addition, dnTEAD2 was inserted into a pLenti_CMV_Puro_DEST vector (Addgene, Cambridge, MA; number 17452) via the Gateway PCR cloning strategy. pLenti-enhanced green fluorescent protein plasmid was purchased from Addgene (number 17448) and used as a control. Short hairpin TEAD4 was purchased from Dharmacon (San Francisco, CA; number RHS4533-EG7004). The pLKO.1 plasmid (empty vector control) was obtained from Addgene (number 10879).

\section{Hydrodynamic Tail Vein Gene Delivery}

All FVB/N mice were purchased from the Jackson Laboratory (Bar Harbor, ME). The hydrodynamic tail vein gene delivery procedure was performed, as described in our previous studies. ${ }^{24,26}$ Briefly, to assess the oncogenic potential of TEAD2VP16, $20 \mu \mathrm{g}$ pT3-EF1 $\alpha$-TEAD2VP16, either alone or in combination with $20 \mu \mathrm{g}$ pT3-EF1 $\alpha$ $\Delta \mathrm{N} 90-\beta$-catenin, was mixed together with $\mathrm{pCMV} /$ sleeping beauty transposase at a ratio of 25:1 and delivered into 6to 8-week-old FVB/N mice via injection into the lateral 
Table 1 Primary Antibodies Used for IHC and WB

\begin{tabular}{|c|c|c|c|c|}
\hline Antibody & Company & Catalog no. & Dilution & Method \\
\hline VP16-tag & Santa Cruz Biotechnology (Dallas, TX) & sc-7545 & $1: 200$ & $\mathrm{IHC}$ \\
\hline Myc-tag & Cell Signaling Technology Inc. (Danvers, MA) & 2978 & $1: 1000$ & WB \\
\hline AFP & Proteintech (Rosemont, IL) & 14550-I-AP & $1: 2000$ & WB \\
\hline DLK1 & Proteintech & 10636-I-AP & $1: 1000$ & WB \\
\hline GAPDH & EMD Millipore (Billerica, MA) & $5174 \mathrm{P}$ & $1: 10,000$ & WB \\
\hline Yap & Cell Signaling Technology Inc. & $4912 S$ & $1: 1000$ & WB \\
\hline Ki-67 & Thermo Fisher Scientific & MA5-14520 & 1:150 & $\mathrm{IHC}$ \\
\hline$\beta$-Catenin & BD Biosciences (San Jose, CA) & 610153 & $1: 200$ & IHC \\
\hline
\end{tabular}

AFP, $\alpha$-fetoprotein; DLK1, $\Delta$-like noncanonical Notch ligand 1; GAPDH, glyceraldehyde-3-phosphate dehydrogenase; IHC, immunohistochemistry; TEAD4, TEA domain transcription factor 4; VP16, virus protein 16; WB, Western blot analysis.

tail vein. To determine whether overexpression of dnTEAD2 affects Yap/ $\beta$-catenin-induced HB formation in mice, $20 \mu \mathrm{g}$ pT3-EF1 $\alpha$-YapS127A and $20 \mu \mathrm{g}$ pT3EF1 $\alpha-\Delta N 90-\beta$-catenin were injected together with $60 \mu \mathrm{g}$ pT3-EF1 $\alpha$-dnTEAD2 or $60 \mu \mathrm{g}$ pT3-EF1 $\alpha$ (empty vector control) and $4 \mu \mathrm{g} \mathrm{pCMV} / \mathrm{sleeping}$ beauty transposase into the mice. Mice were monitored continually and euthanized at specific time points, as indicated in the main text or when they became moribund, as previously described. ${ }^{27}$ Mice were maintained and monitored in accordance with protocols approved by the Committee for Animal Research at the University of California, San Francisco (San Francisco, CA).

\section{Histology, Immunohistochemistry, and Assessment of Mouse Proliferation Rate}

Liver specimens were fixed in $10 \%$ buffered formalin overnight at $4{ }^{\circ} \mathrm{C}$ and embedded in paraffin. Hematoxylin and eosin (Thermo Fisher Scientific, Waltham, MA) staining was performed using a standard protocol on human and mouse liver sections ( $5 \mu \mathrm{m}$ thick) to characterize the hepatocellular lesions histopathologically. For immunohistochemistry, epitope unmasking in deparaffinized sections was used by boiling the slides for 10 minutes in $10 \mathrm{mmol} / \mathrm{L}$ sodium citrate buffer ( $\mathrm{pH}$ 6.0). Then, sections were blocked with 5\% goat serum and the Avidin-Biotin blocking kit (Vector Laboratories, Burlingame, CA), and they were incubated with primary antibodies overnight at $4{ }^{\circ} \mathrm{C}$. The antibodies are listed in Table 1 . Endogenous peroxidase activity was blocked by 20 minutes of incubation of the slides in $3 \% \mathrm{H}_{2} \mathrm{O}_{2}$ (dissolved in methanol). Subsequently, the slides were incubated with secondary antibodies for 1 hour at room temperature. Finally, the reaction signal was visualized using the Vectastain $A B C$ Elite Kit (Vector Laboratories) and developed with 3,3'-diaminobenzidine. Sections were counterstained with hematoxylin. As negative control, slides were incubated with secondary antibodies, omitting the primary antibodies. Images were taken using a bright-field microscope connected to a digital color camera (Leica, San Francisco, CA; model DFC295). The proliferation rate of the hepatocellular lesions was determined by calculating the Ki-67 labeling index in mouse livers. At least 2000 cells were counted for each sample.

\section{Protein Extraction and Western Blot Analysis}

Liver tissues and cells were lysed in protein lysis buffer, which contains $30 \mathrm{mmol} / \mathrm{L}$ tris $(\mathrm{pH} 7.5), 150 \mathrm{mmol} / \mathrm{L} \mathrm{NaCl}$, $0.5 \%$ Na deoxycholate, $1 \%$ Nonidet-P40, $10 \%$ glycerol, $0.1 \%$ SDS, $2 \mathrm{mmol} / \mathrm{L}$ EDTA (Thermo Fisher Scientific), and protease and phosphatase inhibitor. The concentration of proteins was determined with the Bio-Rad Protein Assay Kit (Bio-Rad, Hercules, CA) using bovine serum albumin as a standard. Total protein lysates were denatured by gently mixing with Tris-Glycine SDS Sample Buffer (Bio-Rad) in a heat block for 5 minutes. Equal amounts of proteins were separated by SDS-PAGE gels and transferred to nitrocellulose membranes (Bio-Rad) by electroblotting. Nitrocellulose membranes were blocked for 60 minutes and then incubated with specific antibodies (Table 1) at $4{ }^{\circ} \mathrm{C}$ overnight. After washing, membranes were incubated with a horseradish peroxidase secondary antibody (Jackson Immuno Research Laboratories Inc., West Grove, PA), diluted 1:10,000 for 60 minutes at room temperature and visualized using the Super Signal West Femto (Pierce Chemical Co, New York, NY). ImageJ software version 6.02 (NIH, Bethesda, MD; http:// imagej.nih.gov/ij, accessed February 1, 2018) was used for Western blot densitometric analysis.

\section{RT-qPCR}

Total RNA was extracted from liver tissues or cells using the Quick-RNA MiniPrep Kit (Genesee Scientific, El Cajon, CA). cDNA was generated using the $5 \times$ iScriptTM RT Supermix (Bio-Rad), according to the instructions of the manufacturer. The real-time quantitative RT-PCR (RTqPCR) was performed using the TaqMan Universal PCR Master Mix (Thermo Fisher Scientific) on an ABI Prism 
Table 2 Real-Time Quantitative RT-PCR Primer Sequence Information

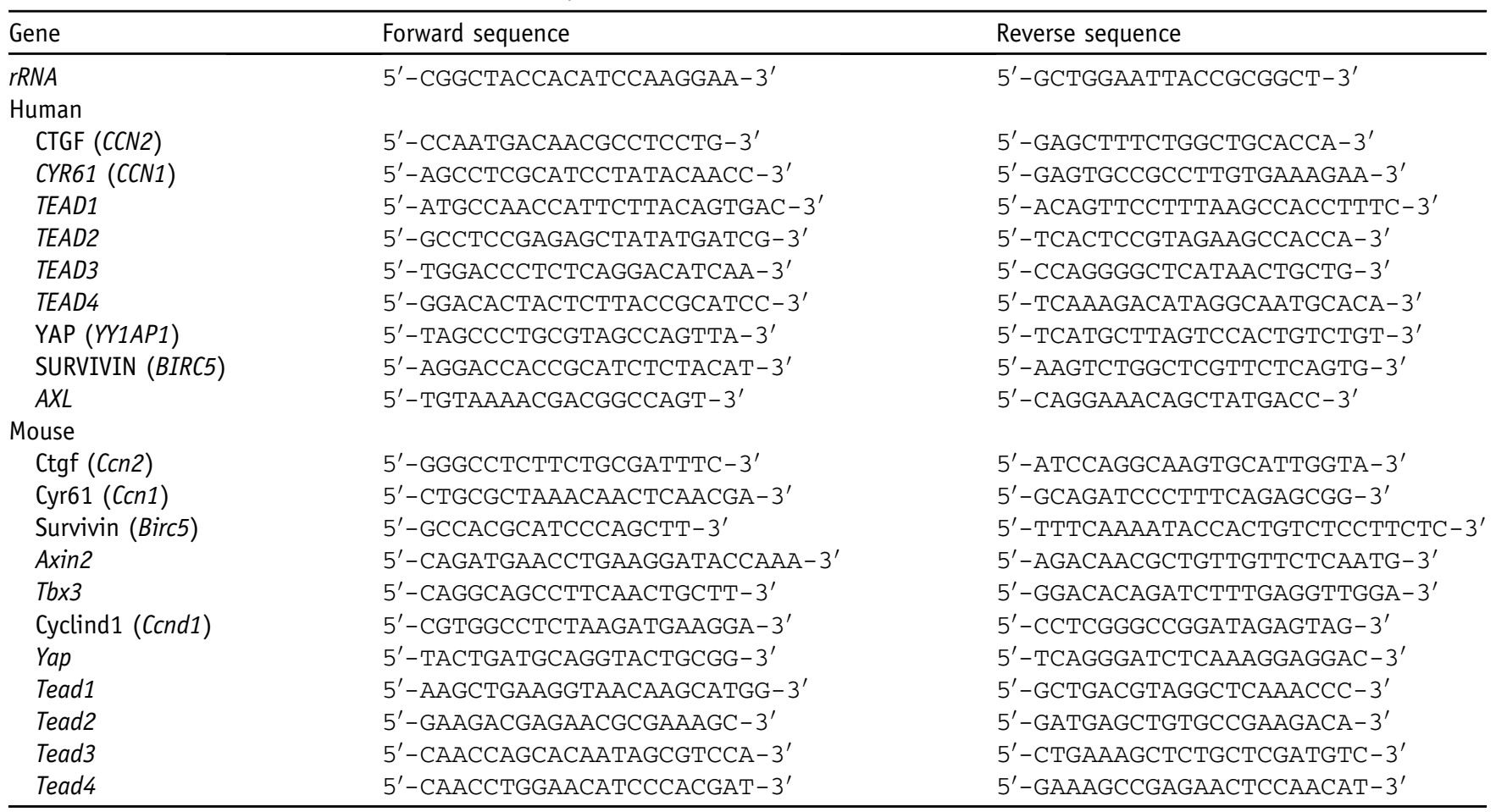

CTGF, connective tissue growth factor; Cyr61, cysteine rich angiogenic inducer 61 .

7000 Sequence Detection System (Applied Biosystems, Foster City, CA). Analysis of mRNA levels was conducted with the QuantStudio Real-Time PCR software version 1.1 (Thermo Fisher Scientific). The RT-qPCR was conducted as follows: template denaturation at $95^{\circ} \mathrm{C}$ for 10 minutes, primer annealing at $95^{\circ} \mathrm{C}$ for 15 seconds, and extension step at $60^{\circ} \mathrm{C}$ for 1 minute. Forty cycles of amplification were used. All the primers used in the present study are listed in Table 2.

\section{In Vitro Studies}

The Hep293TT cell line was a kind gift of Dr. Gail Tomlinson (University of Texas Southwestern Medical Center, Dallas, TX). Cells were cultured in Roswell Park Memorial Institute (RPMI) 1640 medium (Sigma-Aldrich) supplemented with $25 \mathrm{mmol} / \mathrm{L}$ HEPES, $10 \%$ fetal bovine serum (Gibco, Grand Island, NY), $100 \mathrm{U} / \mathrm{mL}$ penicillin, and 100 $\mu \mathrm{g} / \mathrm{mL}$ streptomycin (Sigma-Aldrich). ${ }^{28}$ HepG2 cells, purchased from ATCC (Manassas, VA), were instead cultured in Dulbecco's modified Eagle's medium supplemented with $10 \%$ fetal bovine serum and $1 \%$ penicillin/streptomycin. Cells were grown in a $5 \% \mathrm{CO}_{2}$ atmosphere, at $37^{\circ} \mathrm{C}$. For the colony formation assay, cells were seeded in $100 \times 20$-mm culture dishes and, when they reached 50\% to $60 \%$ confluence, dnTEAD2, enhanced green fluorescent protein, pLKO, or short hairpin TEAD4 lentivirus fluid was added into the culture medium. Seventy-two hours later, the cells were screened, and stable transfected cells were generated by replacing the old medium with fresh medium supplemented with puromycin at the concentration of $2 \mu \mathrm{g} / \mathrm{mL}$ for HepG2 and $1 \mu \mathrm{g} / \mathrm{mL}$ for Hep293TT. After 72 hours of selection, cells were plated at 1000 cells/well for colony formation assays. Two weeks later, colonies were stained with crystal violet and manually counted. To knockdown TEAD genes, cells were seeded in 6-well plates and transfected with 15 pmol siRNA targeting TEAD1-4 (Thermo Fisher Scientific), separately, complexed to Lipofectamine

Table 3 Clinicopathological Features of Human HB Patients

\begin{tabular}{ll}
\hline Variables & Value $^{*}$ \\
\hline No. of patients & 28 \\
Male & 16 \\
Female & 12 \\
$\quad$ Age (years) & \\
Tumor morphology & $4.4 \pm 2.8$ \\
$\quad$ Fetal & \\
Embryonal & 14 \\
Mixed & 8 \\
Recurrence & 6 \\
Yes & \\
No & 10 \\
Lung metastases & 18 \\
Yes & \\
No & 9 \\
\hline
\end{tabular}

*Data are given as number of patients, unless otherwise indicated.

${ }^{\dagger}$ Data are given as means \pm SD.

$\mathrm{HB}$, hepatoblastoma. 


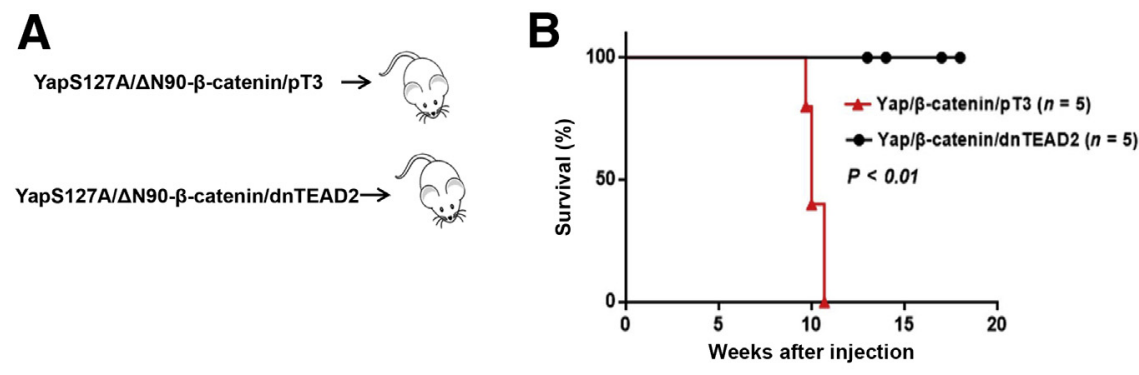

Figure 1 Blockade of Yap-mediated transcriptional regulation via dnTEAD2 suppresses hepatoblastoma growth in mice. A: Study design. B: Survival curve of Yap/ $\beta$-catenin/pT3 and Yap/ $\beta$-catenin/dnTEAD2 mice. C: Gross images, hematoxylin and eosin (H\&E) staining, and Ki-67
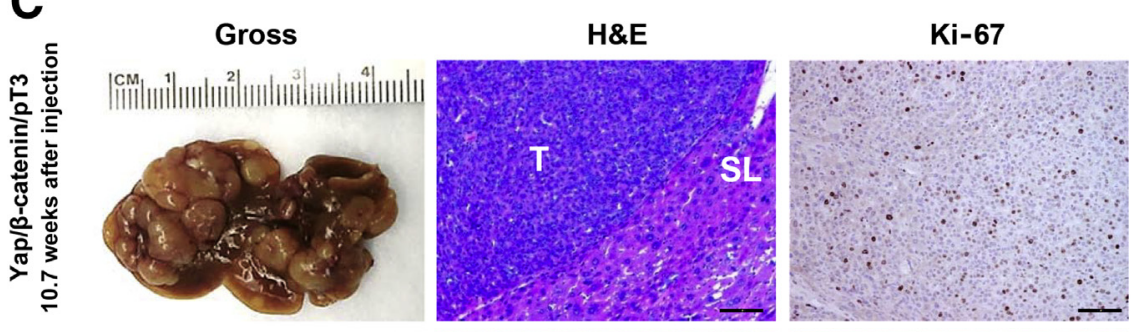
immunohistochemistry of $\mathrm{Yap} / \beta$-catenin/pT3 and Yap/ $\beta$-catenin/dnTEAD2 mouse livers at 10.7 and 17 weeks after hydrodynamic injection, respectively. Arrows indicate the proliferation activity of hepatocytes. $n=5 \mathrm{Yap} / \beta$-catenin/pT3 and Yap/ $\beta$-catenin/dnTEAD2 mice (B). Scale bar $=100 \mu \mathrm{m}$ (C, middle and right columns). Original magnification, $\times 100$ (C). SL, surrounding liver tissues; $\mathrm{T}$, tumor tissues.
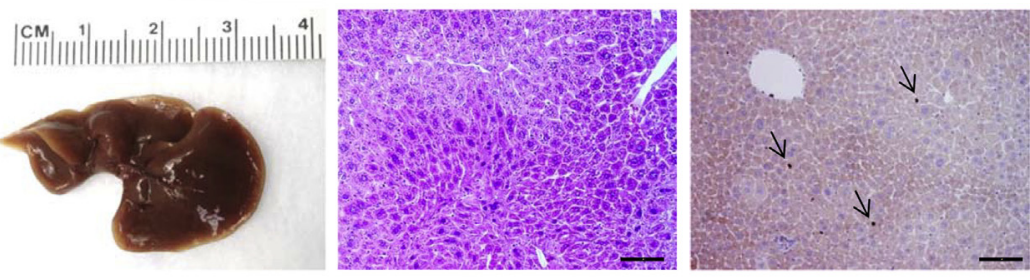

RNAiMAX and Opti-MEMI Reduced Serum Medium (Thermo Fisher Scientific). As control, a scrambled siRNA (number 4390844; Thermo Fisher Scientific) was designed to have no known targets in the cells. Seventy-two hours after transfection, cells were collected for RNA analysis. For cell growth assays, cells were treated with crystal violet staining solution. Subsequently, cells were washed, incubated with lysis solution, and placed on a shaker at room temperature for 20 to 30 minutes. The dissolving solution was added to 96-well plates, and the OD at $590 \mathrm{~nm}$ was measured using a BioTek ELx808 Absorbance Microplate Reader (BioTek Instruments, Inc., Winooski, VT). Transient transfection experiments with TEAD2VP16 and TEAD4 (in pCMV6-Neo plasmid; Origene Technologies Inc., Rockville, MD; number SC111037) constructs were conducted in HepG2 and Hep293TT cell lines using the Lipofectamine 2000 Reagent (Thermo Fisher Scientific). Cell proliferation was determined in human HB cell lines, after 24-hour serum starvation (corresponding to the 0 time point) and 24 and 48 hours later using the bromodeoxyuridine/5-bromo-2'-deoxyuridinex Cell Proliferation Assay Kit (Cell Signaling Technology Inc., Danvers, MA). As concerns apoptosis, two distinct stimuli were applied to HB cells (namely, 24hour serum starvation and staurosporine administration), and apoptotic cell death was assessed using the Cell Death Detection Elisa Plus Kit (Roche Molecular Biochemicals, Indianapolis, IN), following the manufacturer's instructions. Staurosporine (Cell Signaling Technology Inc.) was administered at $1 \mu \mathrm{mol} / \mathrm{L}$ concentration, and apoptosis was evaluated at 4- and 8-hour time points. For both cell proliferation and apoptosis assays, the untreated cells in $0 \%$ serum for 24 hours were used as the baseline, and all values were normalized to the baseline reading. All experiments were repeated at least three times in triplicate.

\section{Human Tissue Samples}

A collection of 28 paraffin-embedded and formalin-fixed human HB specimens, which were previously collected, was used for the present investigation. Liver cancer patients' clinicopathological features are summarized in Table 3. All HB samples were obtained from the archives of the pathology departments of Semmelweis University (Budapest, Hungary) and the Medical University of Greifswald (Greifswald, Germany). The study was performed under the Institutional Review Board approval of the local Ethical Committee of the Medical University of Greifswald and the Regional Ethical Committee of Semmelweis University. Written informed consent was acquired from all the participants.

\section{Statistical Analysis}

All data are presented as means \pm SD for each group. Statistical differences between two groups were determined using the $U$-tests embedded in the Prism 6 software version 6.0 (Graph Pad Software Inc., La Jolla, CA). $P<0.05$ was considered statistically significant. 


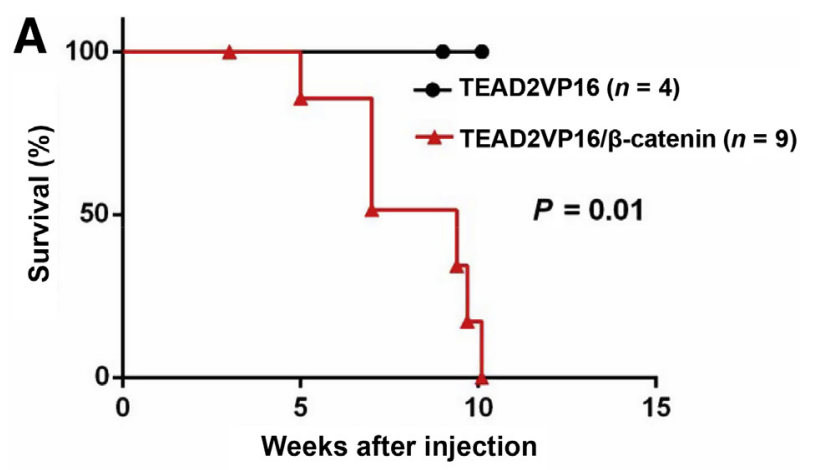

B
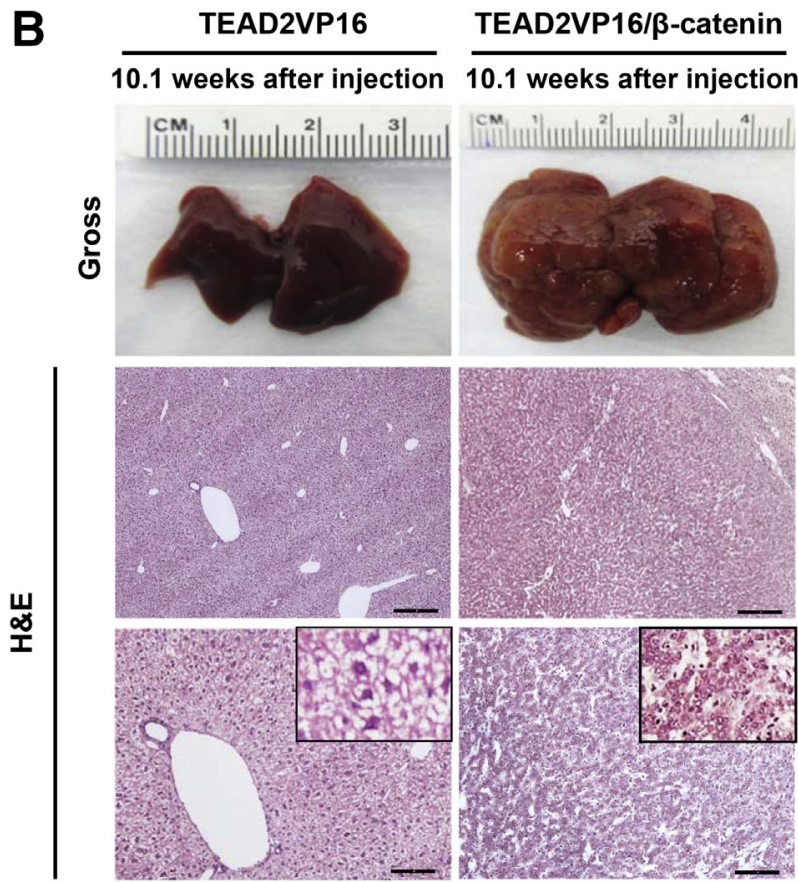

Figure 2 TEAD2VP16 synergizes with $\Delta N 90-\beta$-catenin to promote hepatoblastoma development in mice. A: Survival curve of TEAD2VP16 and TEAD2VP16/ $\beta$-catenin mice. B: Gross images and hematoxylin and eosin (H\&E) staining of TEAD2VP16 and TEAD2VP16/ $\beta$-catenin mouse livers both at 10.1 weeks after hydrodynamic injection. $n=4$ (A, TEAD2VP16 mice); $n=9$ (A, TEAD2VP16/ $\beta$-catenin mice). Scale bars: $250 \mu \mathrm{m}$ (B, middle row); $100 \mu \mathrm{m}$ (B, bottom row). Original magnifications: $\times 40$ (B, middle row); $\times 100$ (B, bottom row); $\times 400$ (B, insets).

\section{Results}

\section{dnTEAD2 Inhibits HB Growth in Vitro and in Vivo}

As a first step to investigate whether TEAD-mediated transcriptional activity is indispensable for Yap-driven HB development, the effect of dnTEAD2 was tested in in vitro and in vivo models of HB. Specifically, dnTEAD2 lacks the DNA-binding domain, which results in nuclear sequestration of Yap and inhibition of its transcriptional activity. ${ }^{25}$

For in vitro experiments, two human $\mathrm{HB}$ cell lines, HepG2 and Hep293TT, were used. The HepG2 cell line was isolated from a 15 -year-old male ${ }^{29}$ and has been widely used as a hepatocellular carcinoma cell line. However, molecular studies have recently shown that it contains a large deletion of exon 3 of the $\beta$-catenin gene and other molecular features that are consistent with its HB nature. ${ }^{30}$ Hep293TT cells were isolated from an HB developed in a 5-year-old male. Similar to HepG2, Hep293TT cells contain a $\mathrm{N}$-terminal deletion of the $\beta$-catenin exon $3 .^{28}$ More important, we have recently shown that YAP is activated in both $\mathrm{HB}$ cell lines. ${ }^{31}$ In light of this body of information, dnTEAD2 was overexpressed in HepG2 and Hep293TT cells. As expected, dnTEAD2 effectively inhibited the expression of Yap downstream targets, such as cysteine-rich angiogenic inducer 61 (CRY61), connective tissue growth factor $(C T G F)$, AXL receptor tyrosine kinase $(A X L)$, and baculoviral IAP repeat containing 5 (BIRC5, alias SURVIVIN) in HepG2 and Hep293TT cells (Supplemental Figure S1A). Forced expression of dnTEAD2 strongly suppressed HepG2 and Hep293TT cell growth in the colony formation assay (Supplemental Figure S1B). Consistently, transient overexpression of dnTEAD2 led to decreased proliferation and increased apoptosis in these cells (Supplemental Figure S2). Overexpression of dnTEAD2 neither influenced the expression levels of $\beta$-catenin and its target genes (glutamine synthetase or GS and T-box 3 or TBX3) (Supplemental Figure S3) nor affected $\beta$-catenin nuclear localization (Supplemental Figure S4) in HepG2 and Hep293TT cells. The results suggest that dnTEAD2 does not regulate the activity of the $\mathrm{Wnt} / \beta$-catenin pathway in $\mathrm{HB}$ cells.

Next, dnTEAD2 was co-expressed with Yap and $\beta$ catenin into the mouse liver (Yap/ $\beta$-catenin/dnTEAD2, $n=5$ ) by hydrodynamic tail vein injection. pT3-EF1 $\alpha$ (empty vector) was also co-injected with Yap and $\beta$-catenin as control (Yap/ $\beta$-catenin/pT3, $n=5$ ) (Figure 1A). Similar to that reported for the Yap/ $\beta$-catenin model, ${ }^{13}$ all mice injected with Yap/ $\beta$-catenin/pT3 developed lethal burden of liver tumor and were euthanized between 10 and 11 weeks after injection (Figure 1B). In striking contrast, all Yap/ $\beta$-catenin/dnTEAD2-injected mice appeared to be healthy, showing no abdominal palpable mass at this time point. Yap/ $\beta$-catenin/dnTEAD2 mice were euthanized between 12 and 18 weeks after injection. On gross inspection, liver tissues from the five Yap/ $\beta$ catenin/dnTEAD2 mice appeared to be completely normal (Figure 1C). Histologically, all liver tumor lesions found in $Y a p / \beta$-catenin $/ \mathrm{pT} 3$ mice were equivalent to those detected in $Y a p / \beta$-catenin-injected mice in previous experiments. ${ }^{13}$ They were classified as mouse HB and were highly proliferating, as demonstrated by Ki-67 immunohistochemical staining (Figure 1C). On the other hand, liver tissues from $Y a p / \beta$-catenin/dnTEAD2 mice appeared to be normal, indistinguishable from normal livers of wild-type mice (Figure 1C). In accordance with morphologic data, the proliferation rate (as assessed by $\mathrm{Ki}-67$ index) of Yap/ $\beta$-catenin/dnTEAD2 livers $(n=5)$ was equivalent to that of normal livers (injected with the empty vector; $n=5)$ at the same time point $(1.7 \pm 0.7$ 

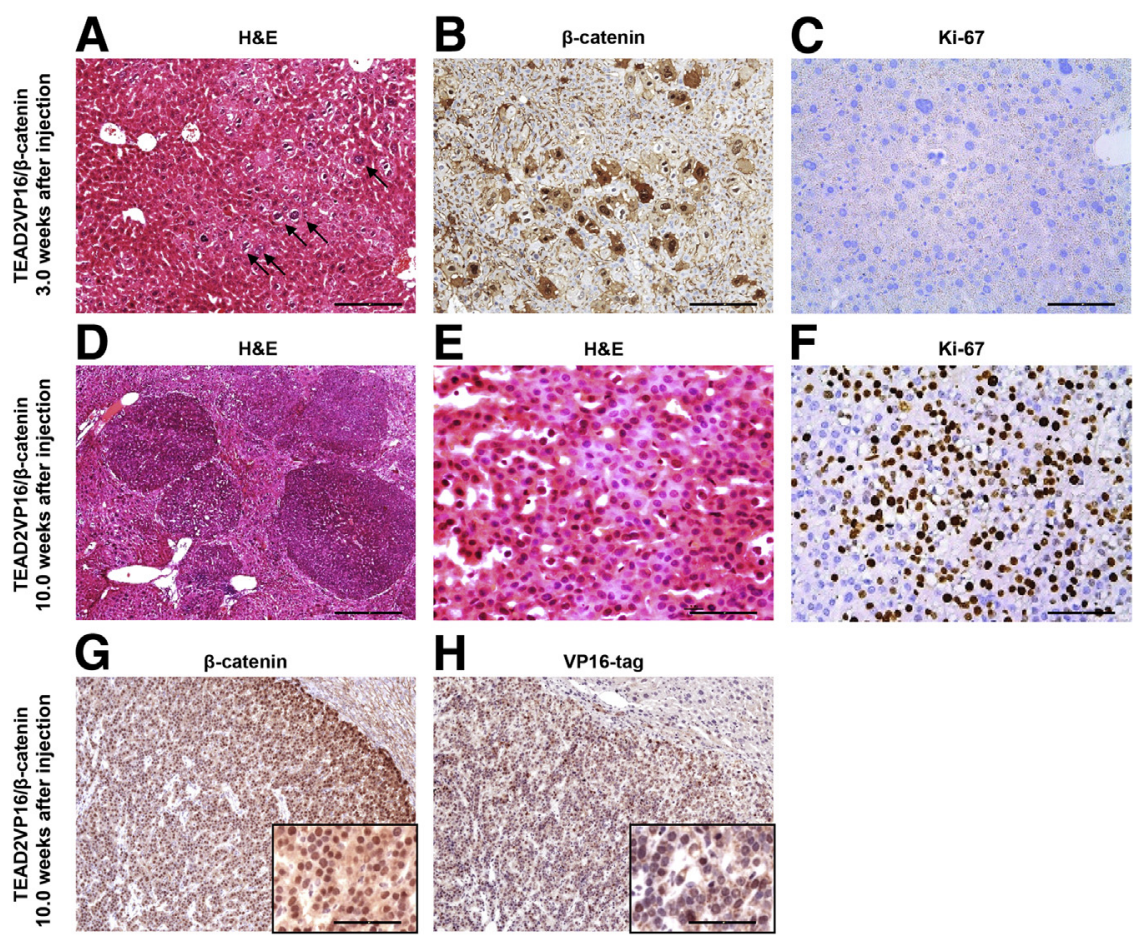

Figure 3 Histopathological and biochemical characterization of liver tumors developed in TEAD2VP16/ $\beta$-catenin and Yap/ $\beta$-catenin mice. A: Hematoxylin and eosin (H\&E) staining of a TEAD2VP16/ $\beta$-catenin mouse liver 3 weeks after hydrodynamic tail vein injection. Altered cells (arrows) were characterized mainly by nuclei of increased size and bizarre shape. B and C: Corresponding representative immunohistochemical images of $\beta$-catenin (B) and Ki-67 (C) in the liver. D-H: Representative H\&E staining (D and $\mathbf{E}$ ) and corresponding images of Ki-67 (F), $\beta$-catenin (G), and VP16 tag $(\mathbf{H})$ staining in the liver from a TEAD2VP16/ $\beta$-catenin mouse 10 weeks after hydrodynamic tail vein injection. Scale bars: $250 \mu \mathrm{m}$ (D); $100 \mu \mathrm{m}$ [A, B, $\mathbf{G}$ (main image), and $\mathbf{H}$ (main image)]; $25 \mu \mathrm{m}$ [C, E, F, G (inset), and $\mathbf{H}$ (inset)]. Original magnifications: $\times 40($ D) $; \times 100[$ A, B, G (main image), and $\mathbf{H}$ (main image)]; $\times 400[\mathrm{C}, \mathrm{E}$, $\mathbf{F}, \mathbf{G}$ (inset), and $\mathbf{H}$ (inset)]. versus $2.0 \pm 0.8$, respectively; not significant), whereas it was significantly higher in Yap/ $\beta$-catenin/pT3 livers $(n=5 ; 31.8 \pm 9 ; P<0.001$ versus both Yap/ $\beta$-catenin/ dnTEAD2 and control livers).

Overall, our study indicates that blockade of Yap/TEAD transcriptional activity via dnTEAD2 suppresses HB cell growth in vitro and tumor development in vivo.

\section{Activated TEAD (TEAD2VP16) Synergizes with $\Delta N 90-\beta$ - Catenin to Promote HB Development in Mice}

Subsequently, it was determined whether Yap/TEADmediated transcriptional activation is sufficient to promote HB development in vivo. To induce TEAD activity in vivo, the pT3-EF1 $\alpha$-TEAD2VP16 construct was generated. This construct consists of the fusion between the N-terminal region of TEAD2, containing the TEA domain, and the activation domain of herpes simplex virus VP16, thus allowing TEAD transcriptional activity independent of Yap. $^{32}$ TEAD2VP16 strictly functions via promoting TEADdependent gene modulation while lacking any other TEAD-independent function of Yap, such as regulating the transforming growth factor- $\beta$ or $\mathrm{Wnt} / \beta$-catenin signaling pathways. $^{32}$

Thus, TEAD2VP16 $(n=4)$ was hydrodynamically transfected either alone or in combination with $\Delta \mathrm{N} 90$ - $\beta$-catenin, into the mouse liver (TEAD2VP16/ $\beta$-catenin, $n=9$ ) (Figure 2). Similar to the results observed when activated Yap was overexpressed alone in the mouse liver, ${ }^{13}$ overexpression of TEAD2VP16 alone did not trigger liver tumor development (Figure 2). The overexpression of $\Delta$ N90- $\beta$ catenin alone is unable to promote liver tumor formation in mice. ${ }^{33}$ In vivid contrast, co-expression of TEAD2VP16/ $\beta$-catenin resulted in massive liver tumor growth, and mice needed to be euthanized approximately 10 weeks after injection because of high tumor burden (Figure 2). The proliferation index was similar between TEAD2VP16-injected $(n=4)$ and control $(n=5)$ mice $(1.5 \pm 0.8$ versus $1.9 \pm 1.0$, respectively; not significant), whereas a much stronger proliferation was detected in TEAD2VP16/ $\beta$-catenin at the same time point $(n=5 ; 24.2 \pm 4.6 ; P<0.001$ versus both TEAD2VP16 and control livers).

Microscopically, altered cells could be appreciated as early as 3 weeks after TEAD2VP16/ $\beta$-catenin injection (Figure $3 \mathrm{~A}$ ) and were positive in the nucleus and cytoplasm for ectopically injected $\beta$-catenin (Figure 3B). At this time point, proliferation was either low or absent (Figure 3C). Tumor nodules started to emerge from the liver parenchyma by 5 weeks (not shown) and occupied most of the hepatic parenchyma by 10 weeks after injection (Figure 3D). Morphologically, the tumor cells were consistent with mouse $\mathrm{HB}$ and were characterized by small tumor cell size and small round or oval nuclei (Figure 3E). All tumor cells showed nuclear staining of ectopically injected $\beta$-catenin (Figure 3G) and VP16 tag (Figure $3 \mathrm{H}$ ). Furthermore, the high proliferation rate of TEAD2VP16/ $\beta$-catenin lesions was underlined by widespread Ki-67 immunoreactivity (Figure 3F).

Next, the biochemical and molecular features of mouse in which HB was induced by Yap/ $\beta$-catenin and TEAD2VP16/ $\beta$-catenin constructs were compared. Using Western blot 

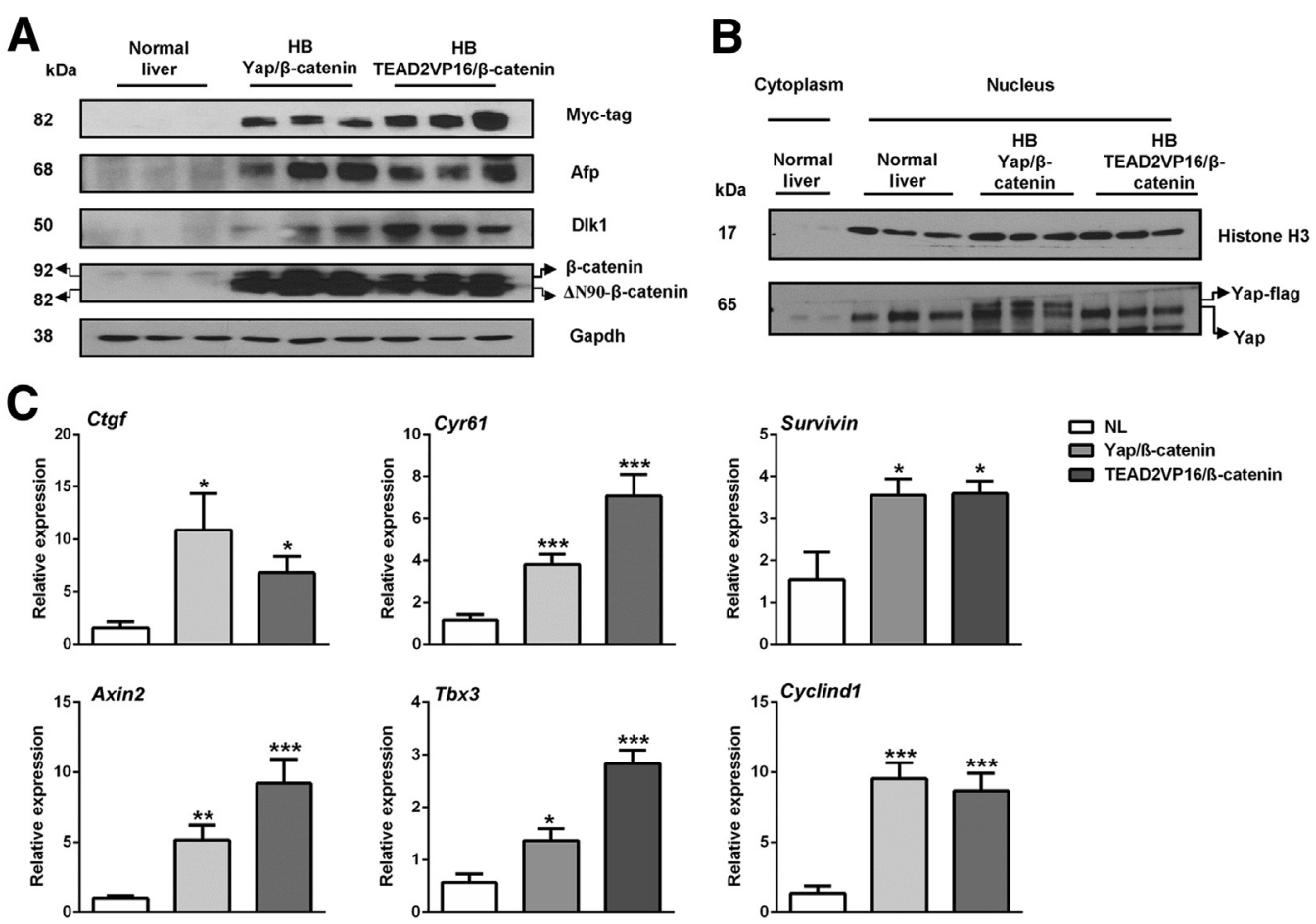

Figure 4 Molecular characterization of liver tumors in TEAD2VP16/ $\beta$-catenin and Yap/ $\beta$-catenin mice. A: Western blot analysis of Myc-tag, $\beta$-catenin, $\alpha$ fetoprotein (Afp), and $\Delta$-like noncanonical Notch ligand 1 (Dlk1) proteins in normal liver (NL) from wild-type FVB/N mice as well as in liver tumors from TEAD2VP16/ $\beta$-catenin and Yap/ $\beta$-catenin mice. Glyceraldehyde-3-phosphate dehydrogenase (Gapdh) was used as the loading control. The image is representative of three independent experiments. B: Western blot analysis of nuclear extracts showing nuclear Yap expression in the liver samples. Histone $\mathrm{H} 3$ was used as the loading control. C: Real-time quantitative RT-PCR was performed to determine the expression levels of Yap and $\beta$-catenin target genes in normal liver and TEAD2VP16/ $\beta$-catenin and Yap/ $\beta$-catenin hepatoblastoma (HB) tissues. Data are expressed as means \pm SD (C). $n \geq 4$ independent replicates (C). ${ }^{*} P<0.05,{ }^{*} P<0.01$, and ${ }^{* * *} P<0.001$ when compared with normal liver (U-test).

analysis, similar levels of ectopically injected Myc-tagged $\beta$-catenin were found in Yap/ $\beta$-catenin and TEAD2VP16/ $\beta$-catenin HB tumor specimens (Figure 4A). Endogenous levels of nuclear and activated Yap could be detected in all normal livers and tumor samples. A higher molecular weight band could be detected in nuclear extracts from Yap/ $\beta$-catenin HB tumors because of the ectopically expressed Flagtagged Yap (Figure 4B). Overexpression of TEAD2/VP16 did not lead to increased levels of nuclear Yap, suggesting that TEAD2/VP16 promotes HB formation independent of Yap activation. Expression of the hepatocellular tumor marker $\alpha$ fetoprotein and the HB marker $\Delta$-like noncanonical Notch ligand 1 was equivalent in Yap/ $\beta$-catenin and TEAD2VP16/ $\beta$-catenin mouse HBs (Figure 4A). In addition, using RTqPCR, we found that Yap/TEAD target genes, such as Ctgf, Cyr61, and Survivin, as well as $\beta$-catenin target genes, including Axin2, $T b x 3$, and cyclin D1, were found to be upregulated in both Yap/ $\beta$-catenin and TEAD2VP16/ $\beta$-catenin HB samples (Figure 4C).

In summary, TEAD2VP16 synergizes with activated $\beta$-catenin to promote mouse $\mathrm{HB}$ development at equivalent latency and efficacy as YapS127A. Thus, TEAD2VP16 recapitulates, at least grossly, YapS127 oncogenic activity in the mouse liver. Altogether, these data suggest that TEAD-mediated transcriptional regulation is both necessary and sufficient for Yap oncogenic action in HB.
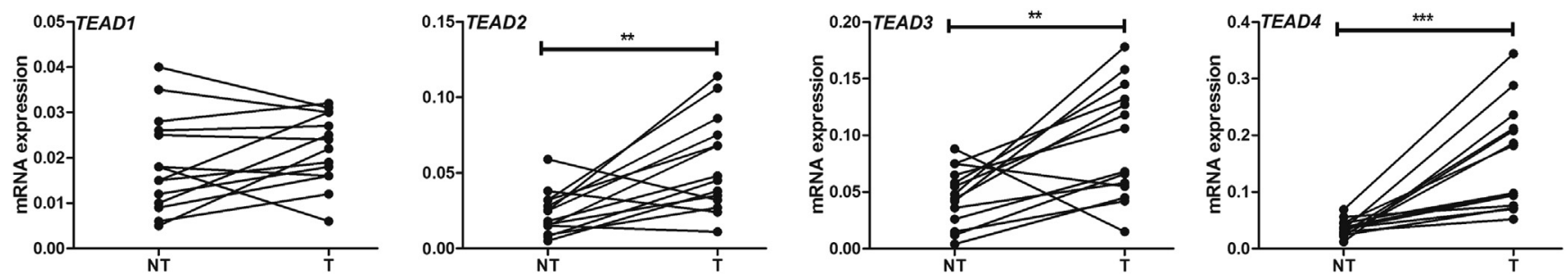

Figure 5 TEAD4 is the predominant TEAD isoform in human hepatoblastoma (HB) samples. Real-time quantitative RT-PCR of TEAD1, TEAD2, TEAD3, and TEAD4 mRNA levels in 14 paired human normal liver and corresponding HB samples. Each symbol represents the mean value of an individual sample. ${ }^{* *} P<0.01,{ }^{* * *} P<0.001$ when compared with normal liver (U-test). NT, nontumorous liver; $\mathrm{T}$, tumor. 
A
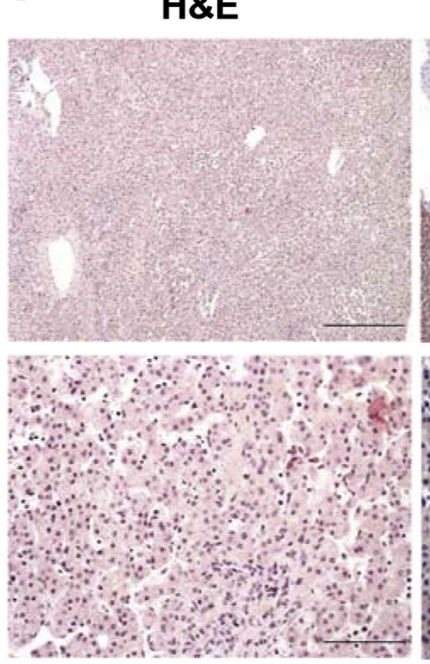

\section{Normal liver}

B
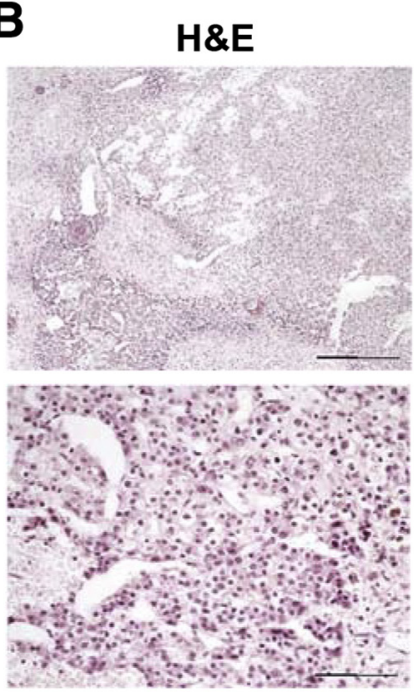

Hepatoblastoma 1
TEAD4
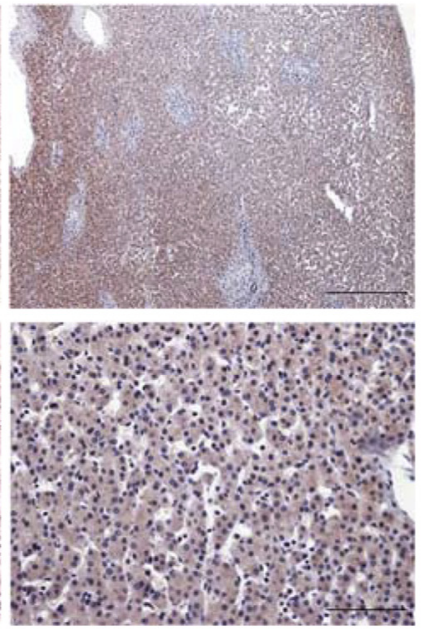

Figure 6 Frequent activation of TEAD4 in human hepatoblastoma (HB) specimens. Immunohistochemical pattern of TEAD4 protein in normal liver $(\mathbf{A})$ and two human HB specimens (B). Normal liver exhibits faint/absent cytoplasmic immunoreactivity for Tead4, whereas HB lesions display strong nuclear accumulation of the protein. The three specimens are depicted in two magnifications. Scale bars: $500 \mu \mathrm{m}$ (A and B, top row); $100 \mu \mathrm{m}$ (A and B, bottom row). Original magnifications: $\times 40$ ( $A$ and $B$, top row); $\times 200$ (A and $B$, bottom row). H\&E, hematoxylin and eosin.

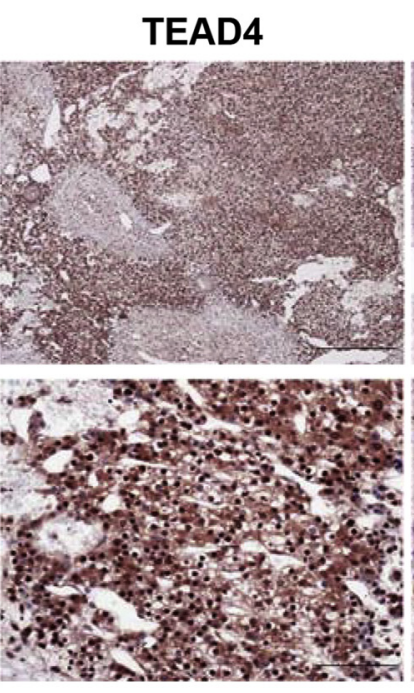

\section{1}

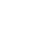

\section{TEAD4 Is the Predominant TEAD Isoform along HB Development}

In mammalian cells, there are four TEAD isoforms (namely, TEAD1, TEAD2, TEAD3, and TEAD4). ${ }^{16}$ The four TEAD proteins bind to similar motifs and, therefore, potentially can all interact with Yap to promote downstream gene expression. Herein, we investigated which TEAD isoform is the most important in HB development. The levels of TEAD1-4 mRNA were assessed by RT-qPCR in a small collection of human HB specimens ( $n=14$ ) (Figure 5). All four TEAD genes were expressed in human $\mathrm{HBs}$ and corresponding nontumorous livers. Statistical analysis revealed that TEAD2, TEAD3, and TEAD4 mRNA levels were significantly up-regulated in human HBs compared with matching nonneoplastic counterparts, whereas TEADl expression was equivalent in tumorous and nontumorous livers. The mRNA findings were in agreement with those that were retrieved from the recent published gene expression array data composed of normal liver tissues $(n=6)$ and human HBs $(n=51)^{7}$ (Supplemental Figure S5). In Yap/ $\beta$-catenin-induced mouse HB models, the expression level of Tead4 mRNA was strongly induced, Teadl expression was moderately up-regulated, and the levels of Tead2 and Tead3 were down-regulated (Supplemental Figure S6). Because it was recently demonstrated that nuclear translocation of TEAD is required for Yap-dependent transcriptional activity, ${ }^{34}$ the cellular expression patterns of TEAD4 were investigated in human HB tumor tissues by immunohistochemistry. Nontumorous liver tissues displayed faint to moderate cytoplasmic staining for TEAD4. In striking 


\section{A HepG2}
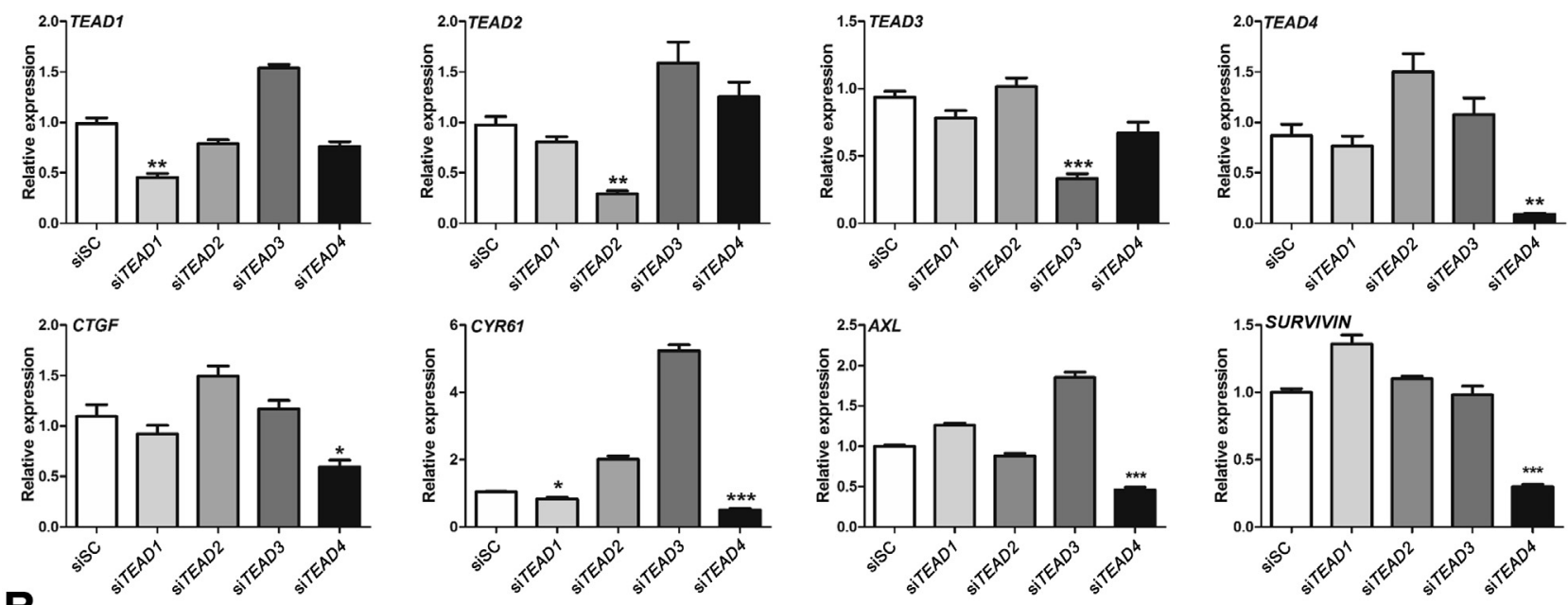

\section{B Hep293TT}
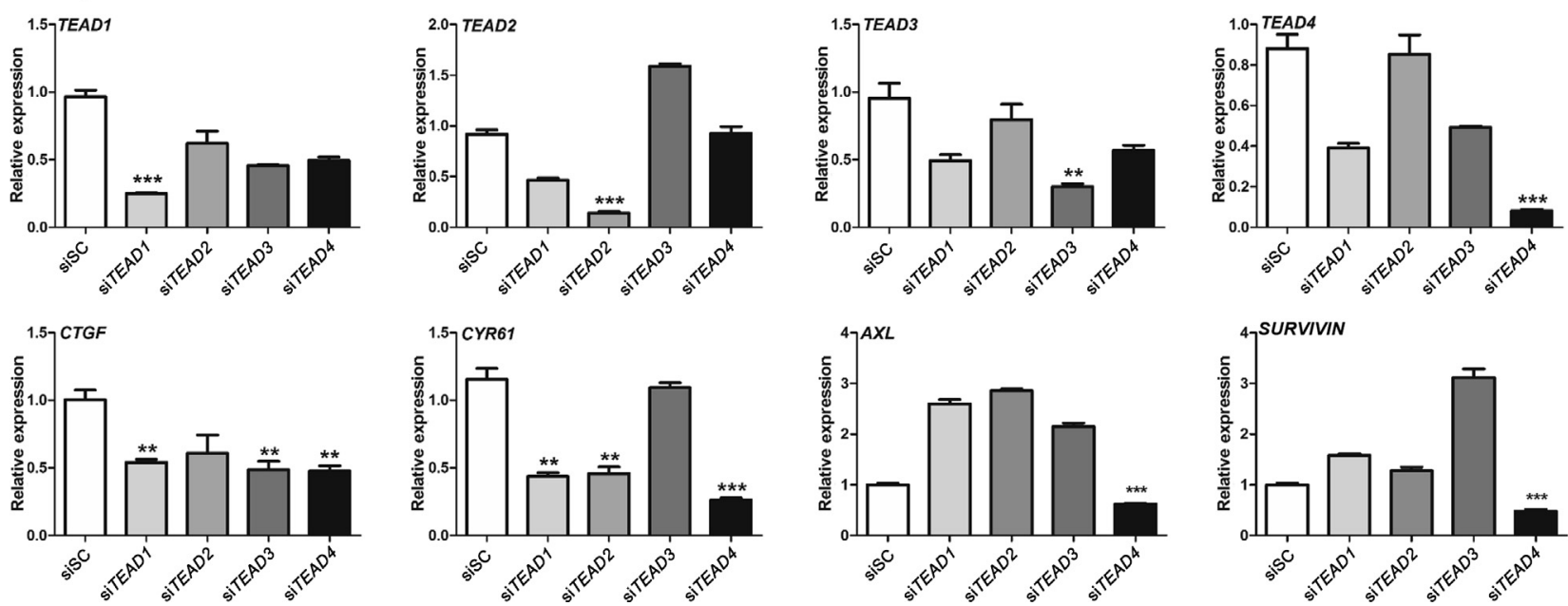

Figure 7 Silencing of TEAD4 inhibits Yap target gene expression in hepatoblastoma (HB) cell lines. HepG2 (A) or Hep293TT (B) human HB cell lines were transfected with scrambled siRNA (siSC), small interfering (si) TEAD1, siTEAD2, siTEAD3, or siTEAD4. The expression of TEAD isoforms as well as that of YAP/ TEAD target genes CTGF, CYR61, AXL, and SURVIVIN were analyzed using real-time quantitative RT-PCR. Data are expressed as means \pm SD (A and $\mathbf{B}) . n=3$ independent replicates $(\mathbf{A}$ and $\mathbf{B}) .{ }^{*} P<0.05,{ }^{*} P<0.01$, and ${ }^{* * *} P<0.001$ when compared with siSC $(U$-test).

contrast, a strong TEAD4 nuclear immunoreactivity was detected in most $(25 / 28 ; 85.7 \%)$ human HB specimens (Figure 6). Similarly, an intense immunolabeling for TEAD4 was detected in the nuclei of HB lesions, but not in surrounding, unaffected tissues, of Yap/ $\beta$-catenin livers (Supplemental Figure S7).

Next, the functional relevance of the four TEAD genes for the Yap transcriptional program was investigated in human $\mathrm{HB}$ cells. TEAD1, TEAD2, TEAD3, and TEAD4 were silenced in HepG2 and 293TT human HB cell lines using specific siRNAs (Figure 7). As expected, each siRNA was effective in silencing the expression of its specific target in both HepG2 and 293TT cells (Figure 7). The expression of Yap/TEAD target genes, including CTGF, CYR61, AXL, and BIRC5, was analyzed after silencing of each TEAD gene. Depletion of TEAD4 significantly inhibited $C T G F$,
CYR61, AXL, and BIRC5 expression in both HepG2 and Hep293TT cells, whereas silencing of TEAD1, TEAD2, and $T E A D 3$ did not lead to consistent down-regulation of these genes in the two human HB cell lines. Consistently, forced overexpression of TEAD4 led to increased levels of YAP target genes in the two HB cell lines (Supplemental Figure S8). In contrast, no effect on the expression levels of $\beta$-catenin targets, such as $G S$ and $T B X 3$, was consistently detected in TEAD4-overexpressed HB cells (Supplemental Figure S8).

Next, it was examined how each TEAD isoform may regulate HB cell growth in vitro. Silencing of TEAD4 led to strong inhibition of proliferation and induction of apoptosis in HepG2 and 293TT cells, whereas intermediate effects on cell growth were detected in TEAD2-silenced cells (Figure 8). Conversely, forced overexpression of TEAD4 by 

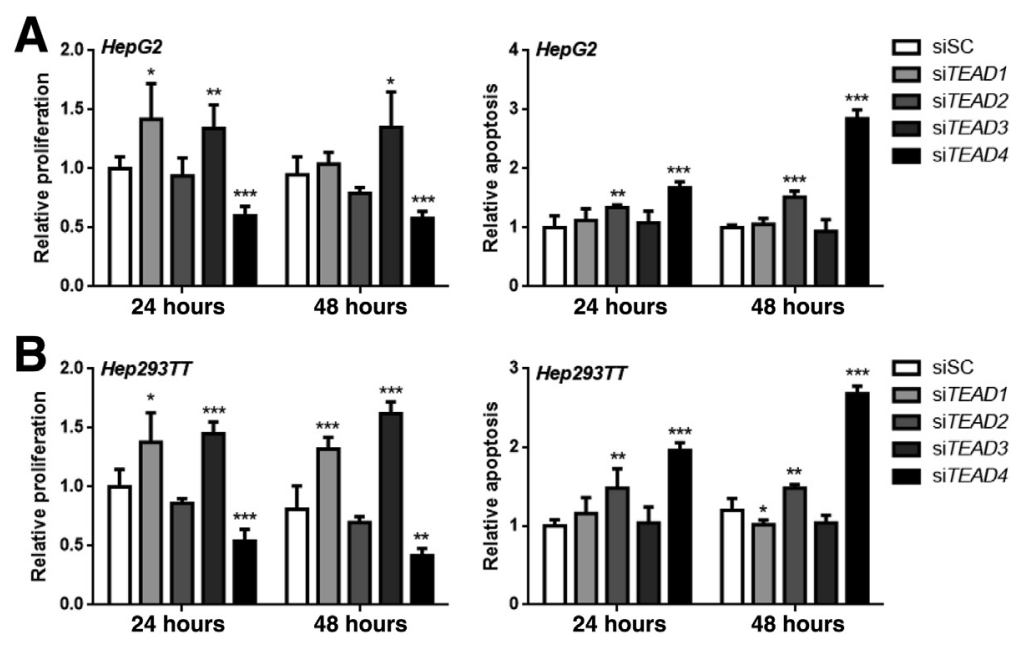

Figure 8 Silencing of TEAD4 decreases proliferation and augments apoptosis in hepatoblastoma (HB) cell lines. HepG2 (A) and Hep293TT (B) human $\mathrm{HB}$ cell lines were transfected with scrambled siRNA (siSC), small interfering (si) TEAD1, siTEAD2, siTEAD3, or siTEAD4. Cell proliferation and apoptosis were measured. Untreated cells cultured in serumfree medium for 24 hours were used as baseline (ie, 1), and all cell proliferation and apoptosis rates were normalized to the baseline values. Data are expressed as means \pm SD (A and $\mathbf{B}$ ). $n=5$ independent replicates $(\mathbf{A}$ and $\mathbf{B}) .{ }^{*} P<0.05$, ${ }^{* *} P<0.01$, and ${ }^{* * *} P<0.001$ when compared with siSC (U-test). transient transfection resulted in a further increase in proliferation and a decline of apoptosis in the two human HB cell lines (Figure 9). In contrast, no significant differences in cell growth or a paradoxical increase in proliferation were detected in TEADI- or TEAD3-depleted cells compared with untreated or scrambled siRNA-treated cells (Figure 8).

To further validate the functional role of TEAD4 in HB biology, TEAD4 expression was abolished using shRNAbased gene depletion. HepG2 and 293TT cells were infected with pLKO.1 or short hairpin TEAD4 lentiviral particles. Similar to siRNA experiments, short hairpin TEAD4 strongly suppressed TEAD4 gene expression in HepG2 and 293TT HB cell lines, leading to the decreased expression of CTGF and CYR61 target genes as well as declined cell growth, as measured by colony formation, proliferation, and apoptosis assays (Supplemental Figure S9).

In summary, these data indicate the up-regulation and activation of TEAD4 in human HBs. Modulation of TEAD4 expression strongly influences HB cell growth inhibition in vitro. Together, these data strongly suggest that TEAD4 is the major TEAD family member mediating Yap transcriptional activity in human HB.

\section{Discussion}

Deregulation of the Hippo pathway with activation of its downstream effector YAP has been implicated in multiple hepatic malignancies, including hepatocellular carcinoma, cholangiocarcinoma, and $\mathrm{HB} .{ }^{35}$ Besides cancer, Yap is also involved in hepatic stellate cell activation and fibrosis ${ }^{36,37}$ as well as in the development of nonalcoholic fatty liver disease. ${ }^{38}$ Overall, these data imply YAP as a key molecule in various liver diseases. In human HBs, YAP is activated in approximately $70 \%$ to $80 \%$ of specimens s $^{13,39}$ and is associated with aggressive or high-risk HBs. ${ }^{7,40}$ Furthermore, it has been found that silencing of YAP reduces human HB cell growth in vitro, whereas overexpression of active Yap cooperates with oncogenic $\beta$-catenin to induce HB formation in mice. ${ }^{13}$ Taken together, this body of
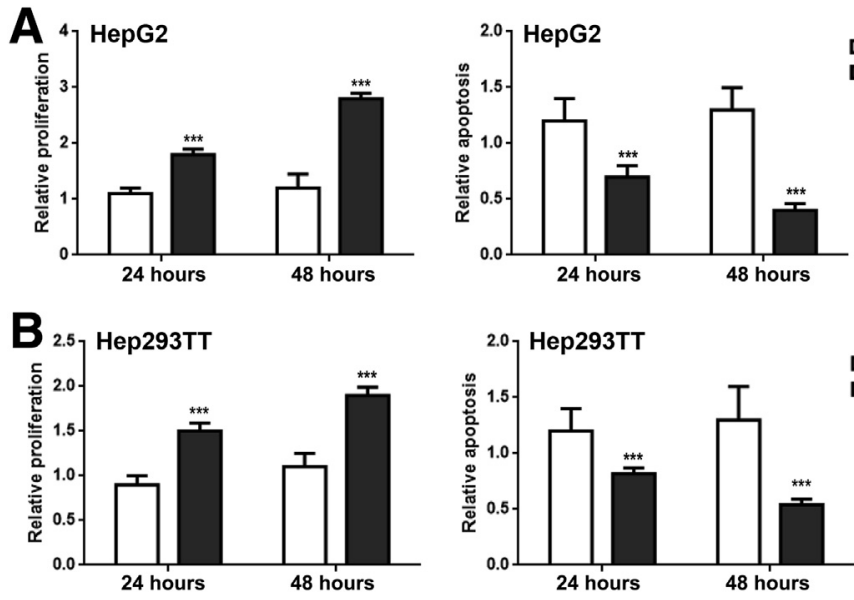

Figure 9 Overexpression of TEAD4 increases proliferation and augments apoptosis in hepatoblastoma (HB) cell lines. HepG2 (A) or Hep293TT (B) human HB cell lines were transfected with empty vector or TEAD4. Cell proliferation and apoptosis were measured. Untreated cells cultured in serum-free medium for 24 hours were used as baseline (ie, 1), and all cell proliferation and apoptosis rates were normalized to the baseline values. Data are expressed as means $\pm S D$ (A and $\mathbf{B}) . n=5$ independent replicates (A and $\mathbf{B}) .{ }^{* * * P}<0.001$ when compared with empty vector (U-test). 
evidence supports a critical role for YAP along HB development and progression. However, how YAP functions to promote HB formation remains poorly understood. Previously, YAP has been shown to interact with TEAD genes to regulate target gene expression. ${ }^{13}$ In addition, YAP possesses many functions that are independent of TEADmediated transcriptional regulation. For instance, in a study by Azzolin et al, ${ }^{19}$ it was found that YAP and its paralog TAZ are sequestered in the $\beta$-catenin destruction complex, together with AXIN and glycogen synthase kinase $-3 \beta$, in the absence of Wnt ligands. In this setting, YAP and TAZ are essential to recruit $\beta$-transducin repeat containing E3 ubiquitin protein ligase to the complex, leading to $\beta$-catenin degradation and inactivation. When Wnt receptors are activated by Wnt ligands, YAP and TAZ are instead released from the destruction complex, ensuring the activation of the $\beta$-catenin cascade. Furthermore, it has been demonstrated that YAP/TAZ control the subcellular localization of activated phosphorylated SMAD2/3. Specifically, cytoplasmic pools of Yap/TAZ sequester phosphorylated SMAD2/3 in the cytoplasm and suppress the transforming growth factor- $\beta$ signaling. ${ }^{20}$ Herein, we tested the hypothesis that YAP acts via TEAD-mediated transcriptional regulation to promote $\mathrm{HB}$ formation in vivo. Blocking TEAD function via dnTEAD2 abolished Yap-driven HB formation. In addition, when TEAD2 was fused with the VP16 transcriptional activator, it functioned in association with activated $\beta$-catenin to enhance the growth of $\mathrm{HB}$ cells in the absence of activated Yap. Taken together, these findings suggest that TEAD-mediated transcriptional regulation is both required and sufficient for Yap-induced HB development. Additional studies are needed to identify the critical target genes regulated by YAP and their role along HB development.

In mammalian cells, four TEAD family members (namely, TEAD1, TEAD2, TEAD3, and TEAD4) have been discovered. By combining gene expression analysis, immunohistochemistry in human HB samples, together with siRNA-based gene silencing and transient transfection in human HB cell lines, it was found that TEAD4 expression is remarkably up-regulated and localized in the nucleus in human HB samples compared with normal liver tissues. Silencing of TEAD4 consistently led to decreased expression of Yap/TEAD target genes and reduced HB cell growth. A completely opposite trend was detected when TEAD4 was instead forcedly overexpressed in HB cell lines. Furthermore, we discovered that TEAD4 suppression results in down-regulation of Yap, whereas TEAD4 overexpression up-regulates it. This implies the possible existence of a feed-forward mechanism reinforcing YAP activation in HB cells. Thus, TEAD4 might be the major TEAD isoform in human HB. In previous studies, TEAD4 was established as the main TEAD isoform in hepatocellular carcinoma development. ${ }^{41,42}$ According to these data, it is tempting to speculate that TEAD4 might represent the key TEAD protein along liver carcinogenesis regardless of the type of tumor. Obviously, this hypothesis requires additional and more thorough validation.

Finally, the present body of evidence suggests that targeting Yap/TEAD-mediated transcriptional regulation is a valid strategy for HB treatment. Consistent with this hypothesis, verteporfin, a small molecule that disrupts YAP/ TEAD interaction, robustly hinders $\mathrm{HB}$ cell growth. ${ }^{13}$ However, verteporfin has many other functions independent of Yap/TEAD and is unlikely to be effective clinically as a YAP/TEAD inhibitor. ${ }^{43}$ Recently, a study demonstrated that Yap and TEAD interact and recruit the Mediator complex (a protein complex that controls various features of transcriptional activation) as well as cyclin-dependent kinase 9 (CDK9) elongating kinases to induce downstream gene expression. ${ }^{43}$ Therefore, targeting CDK9 might be used as an effective approach to disrupt Yap/TEADmediated transcriptional regulation for $\mathrm{HB}$ treatment. It would be of high importance to determine whether CDK9 is required for $\mathrm{HB}$ cell growth and, consequently, the potency of small-molecule CDK9 inhibitors, such as dinaciclib, flavopiridol, or seliciclib, ${ }^{44}$ in inhibiting HB cell growth in vitro and in vivo. Nonetheless, it is worth underlining that these small molecules are not specific for CDK9 and they target multiple cellular processes, including cell cycle regulation ${ }^{45}$ and the unfolded protein response. ${ }^{46}$ The lack of selectivity against other CDKs might limit their clinical use because of possible toxicity. Thus, more specific drugs directed against CDK9 should be developed. Among them, MC180295 ${ }^{47}$ is a newly developed selective CDK9 inhibitor, and it could be tested both in vitro and in vivo, for the treatment of HB.

In summary, this study demonstrates that TEADmediated transcriptional activity is indispensable for Yapdriven HB development, and TEAD4 might be the major TEAD isoform in human HB. Furthermore, the present data support the development and testing of TEAD4 inhibitors as a therapeutic modality for the treatment of human HB.

\section{Acknowledgments}

We thank Dr. Gail Tomlinson (University of Texas Southwestern Medical Center, Dallas, TX) for providing the Hep293TT cell line; Dr. Duojia Pan (Johns Hopkins University, Baltimore, MD) for providing the dominantnegative form of the TEA domain 2 construct; and the Medical University of Greifswald (Greifswald, Germany) and Semmelweis University (Budapest, Hungary) for providing human hepatoblastoma specimens.

\section{Supplemental Data}

Supplemental material for this article can be found at https://doi.org/10.1016/j.ajpath.2019.01.016. 


\section{References}

1. Pateva IB, Egler RA, Stearns DS: Hepatoblastoma in an 11-year-old: case report and a review of the literature. Medicine 2017, 96:e5858

2. Spector LG, Birch J: The epidemiology of hepatoblastoma. Pediatr Blood Cancer 2012, 59:776-779

3. Czauderna P, Lopez-Terrada D, Hiyama E, Haberle B, Malogolowkin MH, Meyers RL: Hepatoblastoma state of the art: pathology, genetics, risk stratification, and chemotherapy. Curr Opin Pediatr 2014, 26:19-28

4. Aronson DC, Meyers RL: Malignant tumors of the liver in children. Semin Pediatr Surg 2016, 25:265-275

5. Meyers RL, Maibach R, Hiyama E, Haberle B, Krailo M, Rangaswami A, Aronson DC, Malogolowkin MH, Perilongo G, von Schweinitz D, Ansari M, Lopez-Terrada D, Tanaka Y, Alaggio R, Leuschner I, Hishiki T, Schmid I, Watanabe K, Yoshimura K, Feng Y, Rinaldi E, Saraceno D, Derosa M, Czauderna P: Risk-stratified staging in paediatric hepatoblastoma: a unified analysis from the Children's Hepatic tumors International Collaboration. Lancet Oncol 2017, 18:122-131

6. Bell D, Ranganathan S, Tao J, Monga SP: Novel advances in understanding of molecular pathogenesis of hepatoblastoma: a Wnt/betacatenin perspective. Gene Expr 2017, 17:141-154

7. Sumazin P, Chen Y, Trevino LR, Sarabia SF, Hampton OA, Patel K, Mistretta TA, Zorman B, Thompson P, Heczey A, Comerford S, Wheeler DA, Chintagumpala M, Meyers R, Rakheja D, Finegold MJ, Tomlinson G, Parsons DW, Lopez-Terrada D: Genomic analysis of hepatoblastoma identifies distinct molecular and prognostic subgroups. Hepatology 2017, 65:104-121

8. Jia D, Dong R, Jing Y, Xu D, Wang Q, Chen L, Li Q, Huang Y, Zhang Y, Zhang Z, Liu L, Zheng S, Xia Q, Wang H, Dong K, He X: Exome sequencing of hepatoblastoma reveals novel mutations and cancer genes in the Wnt pathway and ubiquitin ligase complex. Hepatology 2014, 60:1686-1696

9. Eichenmuller M, Trippel F, Kreuder M, Beck A, Schwarzmayr T, Haberle B, Cairo S, Leuschner I, von Schweinitz D, Strom TM, Kappler R: The genomic landscape of hepatoblastoma and their progenies with HCC-like features. J Hepatol 2014, 61:1312-1320

10. Cairo S, Armengol C, De Reynies A, Wei Y, Thomas E, Renard CA, et al: Hepatic stem-like phenotype and interplay of Wnt/beta-catenin and Myc signaling in aggressive childhood liver cancer. Cancer Cell 2008, 14:471-484

11. Udatsu Y, Kusafuka T, Kuroda S, Miao J, Okada A: High frequency of beta-catenin mutations in hepatoblastoma. Pediatr Surg Int 2001, 17 : 508-512

12. Lee SA, Ho C, Roy R, Kosinski C, Patil MA, Tward AD, Fridlyand J, Chen $\mathrm{X}$ : Integration of genomic analysis and in vivo transfection to identify sprouty 2 as a candidate tumor suppressor in liver cancer. Hepatology 2008, 47:1200-1210

13. Tao J, Calvisi DF, Ranganathan S, Cigliano A, Zhou L, Singh S, Jiang L, Fan B, Terracciano L, Armeanu-Ebinger S, Ribback S, Dombrowski F, Evert M, Chen X, Monga SPS: Activation of betacatenin and Yap1 in human hepatoblastoma and induction of hepatocarcinogenesis in mice. Gastroenterology 2014, 147:690-701

14. Fu V, Plouffe SW, Guan KL: The Hippo pathway in organ development, homeostasis, and regeneration. Curr Opin Cell Biol 2017, 49: 99-107

15. Yu FX, Zhao B, Guan KL: Hippo pathway in organ size control, tissue homeostasis, and cancer. Cell 2015, 163:811-828

16. Lin KC, Park HW, Guan KL: Regulation of the hippo pathway transcription factor TEAD. Trends Biochem Sci 2017, 42:862-872

17. Zhou Y, Huang T, Cheng AS, Yu J, Kang W, To KF: The TEAD family and its oncogenic role in promoting tumorigenesis. Int J Mol Sci 2016, 17. pii: E138

18. Zhang K, Qi HX, Hu ZM, Chang YN, Shi ZM, Han XH, Han YW, Zhang RX, Zhang Z, Chen T, Hong W: YAP and TAZ take center stage in cancer. Biochemistry 2015, 54:6555-6566
19. Azzolin L, Panciera T, Soligo S, Enzo E, Bicciato S, Dupont S, Bresolin S, Frasson C, Basso G, Guzzardo V, Fassina A, Cordenonsi M, Piccolo S: YAP/TAZ incorporation in the beta-catenin destruction complex orchestrates the Wnt response. Cell 2014, 158: $157-170$

20. Varelas X, Samavarchi-Tehrani P, Narimatsu M, Weiss A, Cockburn K, Larsen BG, Rossant J, Wrana JL: The Crumbs complex couples cell density sensing to Hippo-dependent control of the TGFbeta-SMAD pathway. Dev Cell 2010, 19:831-844

21. Tang Y, Feinberg T, Keller ET, Li XY, Weiss SJ: Snail/Slug binding interactions with YAP/TAZ control skeletal stem cell self-renewal and differentiation. Nat Cell Biol 2016, 18:917-929

22. Ho C, Wang C, Mattu S, Destefanis G, Ladu S, Delogu S, Armbruster J, Fan L, Lee SA, Jiang L, Dombrowski F, Evert M, Chen X, Calvisi DF: AKT (v-akt murine thymoma viral oncogene homolog 1) and N-Ras (neuroblastoma ras viral oncogene homolog) coactivation in the mouse liver promotes rapid carcinogenesis by way of mTOR (mammalian target of rapamycin complex 1), FOXM1 (forkhead box M1)/SKP2, and c-Myc pathways. Hepatology 2012, 55: 833-845

23. Marti P, Stein C, Blumer T, Abraham Y, Dill MT, Pikiolek M, Orsini V, Jurisic G, Megel P, Makowska Z, Agarinis C, Tornillo L, Bouwmeester T, Ruffner H, Bauer A, Parker CN, Schmelzle T, Terracciano LM, Heim MH, Tchorz JS: YAP promotes proliferation, chemoresistance, and angiogenesis in human cholangiocarcinoma through TEAD transcription factors. Hepatology 2015, 62:1497-1510

24. Hu J, Che L, Li L, Pilo MG, Cigliano A, Ribback S, Li X, Latte G, Mela M, Evert M, Dombrowski F, Zheng G, Chen X, Calvisi DF: Coactivation of AKT and c-Met triggers rapid hepatocellular carcinoma development via the mTORC1/FASN pathway in mice. Sci Rep 2016, 6:20484

25. Liu-Chittenden Y, Huang B, Shim JS, Chen Q, Lee SJ, Anders RA, Liu JO, Pan D: Genetic and pharmacological disruption of the TEADYAP complex suppresses the oncogenic activity of YAP. Genes Dev 2012, 26:1300-1305

26. Chen X, Calvisi DF: Hydrodynamic transfection for generation of novel mouse models for liver cancer research. Am J Pathol 2014, 184: 912-923

27. Liu P, Ge M, Hu J, Li X, Che L, Sun K, Cheng L, Huang Y, Pilo MG, Cigliano A, Pes GM, Pascale RM, Brozzetti S, Vidili G, Porcu A, Cossu A, Palmieri G, Sini MC, Ribback S, Dombrowski F, Tao J, Calvisi DF, Chen L, Chen X: A functional mammalian target of rapamycin complex 1 signaling is indispensable for c-Myc-driven hepatocarcinogenesis. Hepatology 2017, 66:167-181

28. Chen TT, Rakheja D, Hung JY, Hornsby PJ, Tabaczewski P, Malogolowkin M, Feusner J, Miskevich F, Schultz R, Tomlinson GE: Establishment and characterization of a cancer cell line derived from an aggressive childhood liver tumor. Pediatr Blood Cancer 2009, 53: 1040-1047

29. Aden DP, Fogel A, Plotkin S, Damjanov I, Knowles BB: Controlled synthesis of HBsAg in a differentiated human liver carcinoma-derived cell line. Nature 1979, 282:615-616

30. López-Terrada D, Cheung SW, Finegold MJ, Knowles BB: Hep G2 is a hepatoblastoma-derived cell line. Hum Pathol 2009, 40: $1512-1515$

31. Liu P, Calvisi DF, Kiss A, Cigliano A, Schaff Z, Che L, Ribback S, Dombrowski F, Zhao D, Chen X: Central role of mTORC1 downstream of YAP/TAZ in hepatoblastoma development. Oncotarget 2017, 8:73433-73447

32. Ota M, Sasaki H: Mammalian Tead proteins regulate cell proliferation and contact inhibition as transcriptional mediators of Hippo signaling. Development 2008, 135:4059-4069

33. Tward AD, Jones KD, Yant S, Cheung ST, Fan ST, Chen X, Kay MA, Wang R, Bishop JM: Distinct pathways of genomic progression to benign and malignant tumors of the liver. Proc Natl Acad Sci U S A 2007, 104:14771-14776 
34. Lin KC, Moroishi T, Meng Z, Jeong HS, Plouffe SW, Sekido Y, Han J, Park HW, Guan KL: Regulation of Hippo pathway transcription factor TEAD by p38 MAPK-induced cytoplasmic translocation. Nat Cell Biol 2017, 19:996-1002

35. Yimlamai D, Fowl BH, Camargo FD: Emerging evidence on the role of the Hippo/YAP pathway in liver physiology and cancer. J Hepatol 2015, 63:1491-1501

36. Machado MV, Michelotti GA, Pereira TA, Xie G, Premont R, CortezPinto H, Diehl AM: Accumulation of duct cells with activated YAP parallels fibrosis progression in non-alcoholic fatty liver disease. J Hepatol 2015, 63:962-970

37. Mannaerts I, Leite SB, Verhulst S, Claerhout S, Eysackers N, Thoen LF, Hoorens A, Reynaert H, Halder G, van Grunsven LA: The Hippo pathway effector YAP controls mouse hepatic stellate cell activation. J Hepatol 2015, 63:679-688

38. Chen P, Luo Q, Huang C, Gao Q, Li L, Chen J, Chen B, Liu W, Zeng W, Chen Z: Pathogenesis of non-alcoholic fatty liver disease mediated by YAP. Hepatol Int 2018, 12:26-36

39. Li H, Wolfe A, Septer S, Edwards G, Zhong X, Abdulkarim AB, Ranganathan S, Apte U: Deregulation of Hippo kinase signalling in human hepatic malignancies. Liver Int 2012, 32:38-47

40. Singh V, Manalang M, Singh M, Apte U: A brief report of immunohistochemical markers to identify aggressive hepatoblastoma. Appl Immunohistochem Mol Morphol 2018, 26:654-657

41. Mao B, Hu F, Cheng J, Wang P, Xu M, Yuan F, Meng S, Wang Y, Yuan Z, Bi W: SIRT1 regulates YAP2-mediated cell proliferation and chemoresistance in hepatocellular carcinoma. Oncogene 2014, 33: $1468-1474$

42. Tschaharganeh DF, Chen X, Latzko P, Malz M, Gaida MM, Felix K, Ladu S, Singer S, Pinna F, Gretz N, Sticht C, Tomasi ML, Delogu S, Evert M, Fan B, Ribback S, Jiang L, Brozzetti S, Bergmann F, Dombrowski F, Schirmacher P, Calvisi DF, Breuhahn K: Yes-associated protein up-regulates Jagged-1 and activates the Notch pathway in human hepatocellular carcinoma. Gastroenterology 2013, 144: $1530-1542 . e 12$

43. Galli GG, Carrara M, Yuan WC, Valdes-Quezada C, Gurung B, PepeMooney B, Zhang T, Geeven G, Gray NS, de Laat W, Calogero RA, Camargo FD: YAP drives growth by controlling transcriptional pause release from dynamic enhancers. Mol Cell 2015, 60:328-337

44. Morales F, Giordano A: Overview of CDK9 as a target in cancer research. Cell Cycle 2016, 15:519-527

45. Danilov AV, Hu S, Orr B, Godek K, Mustachio LM, Sekula D, Liu X, Kawakami M, Johnson FM, Compton DA, Freemantle SJ, Dmitrovsky E: Dinaciclib induces anaphase catastrophe in lung cancer cells via inhibition of cyclin-dependent kinases 1 and 2. Mol Cancer Ther 2016, 15:2758-2766

46. Nguyen TK, Grant S: Dinaciclib (SCH727965) inhibits the unfolded protein response through a CDK1- and 5-dependent mechanism. Mol Cancer Ther 2014, 13:662-674

47. Zhang H, Pandey S, Travers M, Sun H, Morton G, Madzo J: Targeting CDK9 reactivates epigenetically silenced genes in cancer. Cell 2018 , 175:1244-1258 